\title{
Utilizando Oficinas Educacionais de Empoderamento Feminino para Inclusão Digital e Social de Estudantes do Ensino Médio
}

\author{
Maria Roselene A. Lima1, Geisiane S. Matos², Sara M. Silva², Fabiola Pantoja \\ O. Araújo ${ }^{2}$, Yomara Pinheiro Pires ${ }^{1}$ \\ ${ }^{1}$ Campus Castanhal - Universidade Federal do Pará (UFPA) Av. dos Universitários, \\ $\mathrm{S} / \mathrm{N}$ - 68746-360 - Castanhal - PA - Brasil \\ ${ }^{2}$ Instituto de Ciências Exatas e Naturais (ICEN) Instituto de Tecnologia (ITEC)- \\ Universidade Federal do Pará (UFPA) Rua Augusto Corrêa, 01- 66075-110 -Belém-PA- \\ Brasil \\ \{roselima.si2016.4, geisi.mattos.s, maru.merces18\}@gmail.com \\ \{fpoliveira, yomara, $\}$ @ufpa.br
}

\begin{abstract}
The purpose of this article is to present the use of information and communication technologies as a means of empowering women, to awaken, in high school girls, the desire to know more about areas of computing. The evaluation was carried out using data extracted from questionnaires, applied during the execution of the workshops. As a result, the satisfaction of the participating students and the desire to learn more about computing and its technologies were identified, with an acceptance level of $85 \%$.
\end{abstract}

Resumo. $O$ objetivo deste artigo é apresentar o uso de tecnologias da informação e comunicação como um meio de empoderamento feminino, para despertar, em meninas do ensino médio, o desejo de conhecer mais sobre áreas da computação. A avaliação foi realizada de dados extraídos de questionários, aplicados durante a execução das oficinas. Como resultado foi identificado a satisfação das alunas participantes e o desejo de aprender mais sobre computação e suas tecnologias, com nível de aceitação em $85 \%$.

\section{Introdução}

Embora hoje as brasileiras correspondam a 57\% da população [PNAD-IBGE, 2018], ainda assim, enfrentam inúmeros problemas relacionados a desigualdade de gênero como. No Ensino Superior, as mulheres correspondem a 52,7\% das matrículas em cursos de graduação [INEP, 2017]. Ao falarmos de cursos do ensino superior em áreas da computação e suas tecnologias, hoje presenciamos uma minoria de mulheres compondo essas turmas em cursos como: Ciência da Computação, Engenharia da Computação e Sistemas de Informação [Grossi, 2016].

Dados apresentados em 2018 pela ONU Mulheres, apontam que 74\% das meninas têm interesse em ciência, tecnologia, engenharia e matemática. No entanto, apenas $30 \%$ das pesquisadoras no mundo são mulheres, somente $18 \%$ dos títulos de graduação em Ciências da Computação são de mulheres e, a força de trabalho feminina na indústria digital, representa $25 \%$ em todo o mundo. No Brasil, dados da SBC indicam que somente $15 \%$ dos alunos matriculados em cursos de Ciência da Computação e Engenharia são mulheres. Para reverter essa situação existem projetos e iniciativas, exemplo disso é o Programa Meninas Digitais, vinculado a SBC desde 2015, que tem como objetivo 
incentivar o ingresso de mulheres na área de computação e no mercado de TI [Meninas Digitais, 2019].

Este artigo tem como objetivo mostrar os resultados iniciais obtidos pelo projeto Meninas Paid'éguas, vinculado ao Programa Meninas Digitais desde 2019, cujo objetivo consiste em despertar o interesse de meninas do Ensino Médio pela área da computação, através de ações como palestras e oficinas, incentivando desta forma o empoderamento feminino, utilizando para isso recursos digitai como o stop motion para a construção de animações, desenvolvendo competências e habilidades por meio de recursos tecnológicos.

\section{Empoderamento feminino e Novas Tecnologias Digitais de Informação e Comunicação (NTDICs)}

A agenda 2030, lançada pela ONU em 2015, estabeleceu 17 Objetivos de Desenvolvimento Sustentáveis (ODS), sendo metas globais transformadoras no mundo [ONU BRASIL 2015]. O quinto ODS trata a igualdade de gênero e tem como foco "Alcançar a igualdade de gênero e empoderar todas as mulheres e meninas". Das nove metas deste conjunto, destacamos a quinta que consiste em "Aumentar o uso de tecnologias de base, em particular as tecnologias de informação e comunicação, para promover o empoderamento das mulheres" [ONU BRASIL 2015].

De acordo com Mombach [2018], quando se trata de empoderamento feminino alinhado ao uso de tecnologias, as mulheres necessitam que seu conhecimento no campo da tecnologia seja reconhecido, uma das alternativas é a promoção de ações onde possam adquirir maior conhecimento sobre tecnologia da informação (TI). Neste sentido, a escolha pela oficina de stop motion visou discutir o empoderamento feminino por meio da utilização de um recurso digital. A proposta buscou aliar o uso de recursos fotográficos para autoaceitação feminina e o desenvolvimento de competências e habilidades de um recurso tecnológico usado para criação de animações como o stop motion.

O stop motion, consiste em uma técnica quadro a quadro, em que é possível utilizar diferentes fotografias de um mesmo objeto inanimado para criar uma ideia de continuidade e ação com recursos de máquina fotográfica, celular, tablet ou computador. Com o stop motion é possível trabalhar os mais diferentes assuntos estudados nas aulas, estimulando a criatividade do aluno e a fixação de conteúdo importante. Dessa maneira, tira-se o aluno da passividade, despertando o protagonismo e trazendo-o para o centro da aprendizagem [Paula e Henrique, 2017].

\section{Materiais e Métodos}

A oficina de stop motion foi desenvolvida de modo teórico-prática e a organização desta atividade foi realizada nas seguintes etapas: a) identificação do perfil das meninas: palestra inicial sobre empoderamento feminino com o intuito de extrair um pouco da realidade de cada participante; b) introdução dos conceitos da técnica de stop motion; c) apresentação do software PIC-PAC stop motion; d) montagem das equipes e produção de animações; e) apresentação das animações produzidas pelo grupo; f) aplicação de um questionário com avaliação socioeconômica, de interação computacional e sobre a aplicação da oficina.

O público participante na oficina do WIT (2019) foram meninas de Bragança Paulista-SP, Castanhal - PA e meninas de Belém - PA, perfazendo um total de 23 meninas. Na oficina realizada na escola de Ensino Médio Agostinho Morais de Oliveira 
no município de Inhangapi, realizada em dezembro de 2019, participaram 12 meninas. Desta forma o universo de pesquisa deste trabalho configura um total de 35 participantes.

\subsection{Relato das Atividades}

As atividades desenvolvidas durante o evento foram: uma palestra inicial sobre o empoderamento feminino e uma conversa rápida para conhecer um pouco da realidade de cada participante. Em seguida montou-se equipes para a realização da oficina, onde houve a montagem de cenários. As ideias para a composição da animação foram baseadas na temática da oficina, que tinha como objetivo o empoderamento feminino, sendo retratado histórias de mulheres que conseguiram sucesso profissional em áreas das Ciências Exatas.

Para que a composição do roteiro fosse desenvolvida, fez-se necessário a construção de um storyboard, utilizando papel, cola, tesoura, lápis de cor, massa de modelar e muita imaginação para que a história contada retratasse algo do universo feminino, trazendo o real para o mundo virtual de maneira lúdica e divertida através do stop motion. Para registrar toda a atividade desenvolvida, utilizou-se o aplicativo PICPAC stop motion, onde foram fotografados todos os momentos de cada cenário e posteriormente transformado em pequenos vídeos, mostrando a elas que se pode trabalhar a computação mesmo sem um computador no ambiente.

Após todas as atividades serem desenvolvidas, foi aplicado um questionário com perguntas referentes ao evento e as atividades realizadas, que posteriormente foram tratados para se chegar aos resultados obtidos através do desenvolvimento do projeto.

\section{Resultados}

Participaram das palestras, oficinas e responderam ao questionário avaliativo um total de 35 meninas. Foram avaliadas todas as respostas para que se obtivesse uma visão da realidade vivida pelas participantes e a necessidade de envolvê-las em mais atividades correlatas. $\mathrm{O}$ questionário utilizado foi dividido em três partes sendo: informações socioeconômicas, interação computacional e sobre as oficinas, visando instigá-las a falar de seus problemas, dúvidas e até mesmo suas visões da sociedade.

Através das informações socioeconômicas, observou-se que participaram dos eventos meninas com faixa etária entre 15 e 48 anos. Ainda sobre a avaliação socioeconômica, foi confirmado que a maioria das participantes (28) estudou todo o ensino fundamental em escola pública, e, que algumas não pretendem fazer a prova do Enem, ficando confirmado o interesse de (25) participantes em cursar um nível superior.

Portanto, é possível destacar que o fato de algumas alunas optarem por ingressar no mercado de trabalho e não prestar um vestibular (Enem), é uma realidade que acontece principalmente em regiões como o município de Inhangapi na Região Nordeste do Estado do Pará, que é uma comunidade ribeirinha que sobrevive da pesca e da agricultura familiar, ficando as jovens comprometidas em ajudar no sustento da família.

As respostas obtidas no questionário de interação computacional, evidenciou que a maioria das participantes (26) possuem acesso à internet e equipamentos tecnológicos, dentre os principais está o smartphone e computador pessoal, que utilizam na sua maioria para acessar redes sociais e pesquisas. Ainda na avaliação sobre interação computacional, foi perguntado sobre o interesse das participantes em cursar um ensino superior em áreas de Computação e tecnologia, como resposta temos o gráfico da Figura 1. 


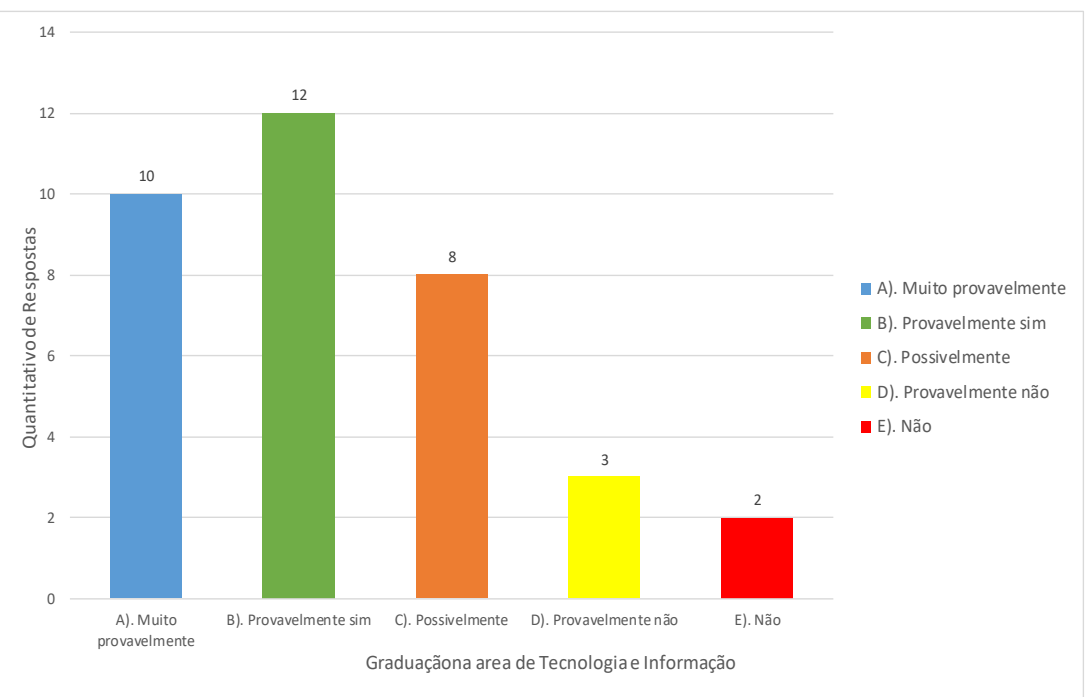

Figura 1. Interesse em áreas da Computação e suas Tecnologias.

Fica evidenciado por meio da análise das respostas da Figura 1, que existe por parte das alunas o interesse em conhecer áreas relacionadas a computação e suas tecnologias, sendo que, apenas 5 participantes não demonstraram interesse pelo campo da computação.

Quanto às respostas obtidas através do questionário sobre as oficinas, obteve-se um resultado positivo, para o material didático utilizado, o grau de satisfação e a motivação das participantes, sendo que 25 participantes avaliaram de forma excelente, 8 como muito bom e 1 como bom.

Quando perguntadas sobre a satisfação em estar participando da oficina e do desenvolvimento de atividades que envolvem tecnologia voltadas para o público feminino, 30 participantes qualificaram como excelente a satisfação em participar das oficinas. Dessa forma é válida a iniciativa em incentivar meninas para as áreas de tecnologias e informação, através do desenvolvimento de atividades práticas, buscando agregar conteúdo prático e teórico de forma lúdica.

As participantes também tiveram a oportunidade de responder a perguntas abertas, referentes ao empoderamento feminino. As perguntas foram sobre: o que é ser menina hoje?; Quais os aspectos positivos de ser menina?; O que é ser empoderada? O que você como menina gostaria de aprender em computação? Obteve-se resposta coerentes e simples e que demonstram o sentimento comum do enfrentamento diário que mulheres vivem na sociedade: "É uma luta diária de aceitação, conscientização, ao sofrer preconceito, simplesmente por ser mulher em várias situações".

Diante desses resultados percebe-se um grande interesse das meninas pela área da computação e tecnologias, quando nas avaliações se torna perceptível a satisfação e motivação das alunas em desenvolver as atividades.

\section{Considerações Finais}

O objetivo inicial desse projeto foi trazer temas e discussões sobre empoderamento feminino, com o intuito de incentivar o ingresso de meninas nas áreas tecnológicas como, computação e para o mercado de TI. Percebeu-se que o assunto ainda é algo novo e pouco discutido, ou discutido apenas em pequenos grupos. Considerando essas informações, o 
Meninas Paid'éguas, através de parcerias com escolas públicas procurou desenvolver atividades que incentivassem o interesse de meninas do ensino médio para os cursos de Ciências Exatas.

As oficinas e as palestras se mostraram instrumentos de muita importância no despertar do interesse de participação das meninas no evento, bem como viabilizou a interação entre os grupos, conseguindo assim estimular a curiosidade em relação ao modo de como se ver as áreas de computação e suas tecnologias. Dados os objetivos propostos neste projeto, pode-se avaliar que os mesmos foram atingidos. Observou-se nos relatos que algumas meninas expressam sinais mais visíveis de empoderamento e o interesse de aprender mais sobre computação e suas áreas.

Portanto, como sugestão para trabalhos futuros, seria elaborar um cronograma para divulgar o projeto e obter um maior alcance às alunas do ensino médio e assim consolidar o objetivo que é incentivar o maior número possível de meninas para a conhecerem áreas da computação e tecnologias, promovendo uma maior integração, sororidade e empoderamento dessas meninas.

\section{Referências}

Aplicativo Pic-Pac stop motion. Disponível em:<https://play.google.com/store/apps/details?id=tv.picpac\&hl=pt_BR/>. Acesso em março, 2020.

Grossi, Márcia G. R. et al (2016). As mulheres praticando ciência no Brasil. Revista Estudos Femininos. Florianópolis. Vol.24 no.1, 2016.

Instituto Brasileiro de Geografia E Estatística - IBGE. Pesquisa Nacional por Amostras de Domicílio Contínua - PNAD (2018). Disponível em: 〈http://. ibge.gov.br〉. Acesso em março, 2020.

Instituto Nacional de Estudos e Pesquisas Anísio Teixeira - INEP. (2019). Disponível em: <http://portal.inep.gov.br/web/guest/inicio>. Acesso em março, 2020.

Mombach, Jaline, et al. "Práticas de Criação de Aplicativos Móveis como Estratégia para o Empoderamento Feminino." Anais do Workshop de Informática na Escola. Vol. 24. No. 1. 2018.

ONU Brasil (2015). Transformando nosso mundo: A agenda 2030 para o desenvolvimento sustentável. https://nacoesunidas.org/pos2015/agenda2030/. Acesso em 11 de março de 2020.

J. L. Paula; A. L. S. Henrique. O uso do stop-motion como prática pedagógica no ensino de geografia no contexto do EMI. Revista HOLOS. Rio Grande do Norte. Ano 33, Vol. 03, 2017.

Programa Meninas Digitais. (2019). Disponível em: $<$ http://meninas.sbc.org.br/>. Acesso em março, 2020.

Santana, Thalia S., et al. "A importância de atividades de empoderamento feminino como forma de minimizar a evasão das mulheres nos cursos de Tecnologia da Informação." Anais do XI Women in Information Technology. SBC, 2017. 